\title{
Ácido indolbutírico na estaquia de Calliandra brevipes e Calliandra tweedii
}

\author{
Natália Saudade de Aguiar $\mathbb{(}^{1 *}$ Cassiano Emilio de Sousa $\mathbb{0}^{2}$ Giovana Beger $\mathbb{0}^{2}$ Katia Christina \\ Zuffellato-Ribas $\mathbb{1}^{3}$
}

${ }^{1}$ Universidade Federal do Paraná, Av. Pref. Lothário Meissner, 632, Jardim Botânico, CEP 80210-170, Curitiba, PR, Brasil

${ }^{2}$ Universidade Federal do Paraná, Rua dos Funcionários, 1540, Juvevê, CEP 80035-050, Curitiba, PR, Brasil

${ }^{3}$ Universidade Federal do Paraná, Av. Coronel Francisco Heráclito dos Santos, 100, Jardim das Américas, CEP 81531-980, Curitiba, PR, Brasil

Original Article
*Corresponding author:
talia.saguiar@yahoo.com.br
Palavras-chave:
Auxina
Estaquia
Plantas ornamentais
Regulador vegetal
Keywords:
Auxin
Cuttings
Ornamental plants
Plant growth regulators
Received in
2020/06/04
Accepted on
2021/25/01
(cc) Bublished in
2021/30/06
(c)

RESUMO: Calliandra brevipes e Calliandra tweedii são espécies leguminosas muito utilizadas como plantas ornamentais devido a seu porte arbustivo e floração vistosa. Visando tornar mais eficiente o protocolo de produção de mudas dessas espécies por meio da propagação vegetativa, o objetivo deste trabalho foi avaliar o enraizamento de estacas caulinares semilenhosas de $C$. brevipes e $C$. tweedii mediante a aplicação de diferentes concentrações de ácido indolbutírico (IBA). As quatro concentrações de IBA testadas foram: $0 \mathrm{mg} \mathrm{L}^{-1}$ (controle); $1500 \mathrm{mg} \mathrm{L}^{-1}$; $3000 \mathrm{mg} \mathrm{L}^{-1}$; e $6000 \mathrm{mg} \mathrm{L}^{-1}$. As estacas foram plantadas em tubetes de polipropileno com vermiculita de granulometria fina e após 65 dias em casa de vegetação foi avaliado o enraizamento das estacas, número de raízes por estaca, comprimento das três maiores raízes por estaca, retenção de folhas e emissão de brotações, estacas com calos, vivas e mortas. A aplicação do ácido indolbutírico não afetou a taxa de enraizamento, mas proporcionou o aumento do número de raízes para ambas as espécies. Entretanto, altas concentrações de IBA reduziram o comprimento de raízes em $C$. brevipes. Dessa forma, recomenda-se a utilização de ácido indolbutírico na concentração de $1500 \mathrm{mg} \mathrm{L}^{-1}$ na propagação vegetativa de $C$. brevipes e $C$. tweedii, visando o melhor desenvolvimento do sistema radicial. $C$. brevipes apresentou melhor enraizamento que $C$. tweedii, com maior porcentagem de estacas enraizadas $(95,83 \%$ e $64,17 \%$, respectivamente), maior número e comprimento de raízes, maior retenção de folhas, bem como emissão de brotações.

\section{Indolebutyric acid in Calliandra brevipes and Calliandra tweedii cuttings}

\begin{abstract}
Calliandra brevipes and Calliandra tweedii are widely used as ornamental plants due to their bush shape and exuberant flowering. Aiming to develop an efficient protocol for vegetative propagation of these species, the purpose of this paper was to evaluate the rooting of semi-woody stem cuttings of C. brevipes e C. tweedii submitted to concentrations of indolebutyric acid (IBA). The treatments consisted of four IBA concentrations: $0 \mathrm{mg} \mathrm{L}^{-1}$ (control); $1500 \mathrm{mg}$ $\mathrm{L}^{-1} ; 3000 \mathrm{mg} \mathrm{L}^{-1}$; and $6000 \mathrm{mg} \mathrm{L}^{-1}$. The cuttings were planted in $53 \mathrm{~cm}^{3}$ tubes filled with vermiculite. After 65 days in greenhouse, the following variables were evaluated: rooting percentage, number of roots per cutting, mean of 3 lengthiest roots, percentage of maintenance of the initial leaves, percentage of bud cuttings, cuttings with calluses, survival and mortality. In most of the analyzed variables IBA concentrations did not influence rooting process. Application of indolebutyric acid increased the number of roots for both species, but reduced root length in $C$. brevipes. Thus, it is recommended the use indolebutyric acid at a concentration of $1500 \mathrm{mg} \mathrm{L}^{-1}$ in C. brevipes and C. tweedii cuttings, for the best development of the root system. $C$. brevipes showed better rooting than $C$. tweedii, obtaining a higher percentage of rooted cuttings ( $95.83 \%$ and $64.17 \%$, respectively), higher number and length of roots, percentage of maintenance of the initial leaves and bud cuttings.
\end{abstract}


Introdução

Calliandra brevipes Benth. (sinonímia botânica Calliandra selloi (Spreng.) J.F.Macbr.) e Calliandra tweedii Benth. são espécies nativas do Brasil e pertencem à família Leguminosae (Mimosoideae). As espécies diferenciam-se especialmente pela cor dos estames florais e número de folíolos por folha. C. brevipes possui estames branco-rosados e folhas com um par de folíolos; enquanto $C$. tweedii apresenta estames vermelhos e folhas com número de folíolos variando de 3 a 5 pares (Miotto et al. 2008). Ambas as espécies possuem ampla utilização como plantas ornamentais devido ao porte arbustivo, floração vistosa, tolerância a podas, forma de copa, folhagem densa e rusticidade (Cardoso et al. 2007; Miotto et al. 2008; Mondin et al. 2010). As espécies $C$. brevipes e $C$. tweedii podem ser propagadas por sementes ou via estaquia (Mondin et al. 2010), mas são poucos os trabalhos encontrados na literatura com a propagação destas espécies.

A estaquia é um dos processos de propagação vegetativa mais empregados para o resgate de matrizes selecionadas e obtenção de mudas clonais (Konzen et al. 2018). Essa técnica vem sendo utilizada para a propagação clonal de espécies ornamentais, frutíferas e florestais. Possui diversas vantagens como: possibilidade de multiplicação de espécies em que o método sexuado é dificultado; produção de mudas em menor período em comparação com a propagação por sementes; e floração e frutificação precoces (Xavier et al. 2009; Hartmann et al. 2014). Para culturas ornamentais e frutíferas as técnicas de propagação vegetativa, como a estaquia, apresentam várias vantagens frente a propagação via sementes, como a redução do período improdutivo, antecipando a floração (Mayer et al. 2008), de grande relevância para espécies ornamentais atrativas pelas suas flores, como é o caso das espécies $C$. brevipes e $C$. tweedii.

A técnica de estaquia depende da formação de raízes adventícias nos propágulos; entretanto, para que ocorra o enraizamento é necessário um balanço adequado entre auxinas, giberelinas, citocininas e cofatores do enraizamento (Hartmann et al. 2014). A auxina desempenha um papel central no enraizamento, iniciando o processo de formação e alongamento de raízes adventícias (Erturk et al. 2010) e interagindo com outros hormônios vegetais envolvidos no processo rizogênico (Pacurar et al. 2014). A literatura reporta diversos trabalhos nos quais a aplicação de reguladores vegetais apresenta um efeito positivo no enraizamento de estacas de muitas espécies lenhosas (Dias et al. 2012). Entre as auxinas sintéticas, o ácido indolbutírico (IBA) tem sido a mais utilizada atualmente, devido a maior capacidade de indução do enraizamento em grande parte das espécies estudadas e maior estabilidade à luz (Pacurar et al. 2014).
C. brevipes é considerada como uma espécie de fácil enraizamento; porém, estudos com $C$. tweedii reportaram baixas porcentagens de enraizamento, mesmo com a aplicação de reguladores vegetais (Lima et al. 2006; Mayer et al. 2008). Assim, o objetivo do presente trabalho foi avaliar o enraizamento de estacas caulinares semilenhosas de $C$. brevipes e $C$. tweedii submetidas a quatro concentrações de ácido indolbutírico.

\section{Material e métodos}

Ramos de três plantas matrizes de $C$. brevipes e C. tweedii foram coletados no Campus Jardim Botânico da Universidade Federal do Paraná, Curitiba - PR (25 26' 41' S, 49 14' 19” O), em agosto de 2019. As espécies foram diferenciadas pelas inflorescências e número de folíolos (Miotto et al. 2008). As matrizes de C. tweedii apresentavam inflorescências e alguns frutos, enquanto os indivíduos de $C$. brevipes não possuíam estruturas reprodutivas no momento da coleta.

Para as duas espécies foram confeccionadas estacas caulinares semilenhosas, de aproximadamente $8 \mathrm{~cm}$ de comprimento, corte reto no ápice e em bisel na base da estaca, sendo mantidas duas folhas com um par de folíolos no ápice da estaca. A desinfestação do material foi realizada pela imersão das estacas em solução aquosa de hipoclorito de sódio a $0,5 \%$ durante 15 minutos e lavagem em água corrente por 5 minutos.

Posteriormente, as bases das estacas foram imersas em ácido indolbutírico (IBA), solução hidroalcoólica (1:1), por 10 segundos. Os tratamentos consistiram em quatro concentrações de IBA: $0 \mathrm{mg} \mathrm{L}^{-1}$ (controle); $1500 \mathrm{mg} \mathrm{L}^{-1}$; $3000 \mathrm{mg} \mathrm{L}^{-1}$; e $6000 \mathrm{mg} \mathrm{L}^{-1}$. O plantio das estacas foi realizado em tubetes de polipropileno de $53 \mathrm{~cm}^{3}$ preenchidos com vermiculita de granulometria fina e as estacas foram mantidas em casa de vegetação climatizada $(25 \pm$ $2^{\circ} \mathrm{C}, 85 \%$ UR) por 65 dias. O experimento foi instalado em delineamento inteiramente casualizado (DIC), esquema fatorial $2 \times 4$ (2 espécies e 4 concentrações de IBA) com 4 repetições de 15 estacas, totalizando 60 estacas por tratamento.

Após 65 dias em casa de vegetação todas as estacas foram avaliadas, sendo classificadas como: enraizadas (presença de raízes com no mínimo $2 \mathrm{~mm}$ de comprimento); estacas com calos (estacas vivas, sem raízes, com formação de massa celular indiferenciada na base); estacas vivas (não apresentavam calos e raízes); e estacas mortas (base das estacas com tecido necrosado). Além disso, foram avaliadas as variáveis: número de raízes por estaca; comprimento das três maiores raízes por estaca; retenção de folhas; e emissão de brotações. 
$\mathrm{Na}$ análise estatística as pressuposições de distribuição normal dos resíduos e homogeneidade das variâncias foram verificadas pelos testes de Shapiro Wilk $(P<0,05)$ e de Levene $(P<0,05)$, respectivamente. Sendo aceitas as pressuposições anteriores, prosseguiu-se com a análise de variância (ANOVA) e comparação de médias pelo teste de Tukey $(P<0,05)$.

\section{Resultados e discussão}

As concentrações de IBA não influenciaram as porcentagens de estacas enraizadas, retenção de folhas, emissão de brotações, estacas com calos, vivas e mortas, para as espécies avaliadas. A variável número de raízes por estaca diferiu entre as concentrações de IBA e o comprimento das três maiores raízes apresentou interação entre os fatores. Todas as variáveis diferiram significativamente entre as espécies $C$. brevipes e $C$. tweedii (Tabela 1).

\section{Efeitos das concentrações de IBA}

A porcentagem de estacas enraizadas não foi afetada pelas concentrações de IBA nas duas espécies (Tabela 2). Esse resultado já era esperado para $C$. brevipes por ser uma espécie de fácil enraizamento (Lima et al., 2006), sendo que os trabalhos de Lima et al. (2006) e Mayer et al. (2008) já haviam demonstrado que a aplicação de reguladores vegetais não influencia de forma significativa no enraizamento desta espécie. Entretanto, esperava-se que $C$. tweedii respondesse positivamente à aplicação da auxina sintética, já que para Mayer et al. (2008) a maior porcentagem de enraizamento foi obtida na maior concentração de IBA avaliada, $2000 \mathrm{mg} \mathrm{L}^{-1}$. Dessa forma, é possível afirmar que a aplicação de IBA em maiores concentrações, até $6000 \mathrm{mg} \mathrm{L}^{-1}$, não promoveu o aumento da taxa de enraizamento para as espécies avaliadas; indicando que possivelmente as estacas possuíam uma quantidade endógena suficiente de auxinas para promover a formação de raízes adventícias (Bitencourt et al. 2009).

A aplicação do regulador vegetal, em todas as concentrações utilizadas, promoveu o desenvolvimento de maior número de raízes por estaca quando comparado com o tratamento controle. As concentrações de IBA avaliadas (1500, 3000 e $6000 \mathrm{mg} \mathrm{L}^{-1}$ ) não diferiram entre si, entretanto, pode-se observar uma tendência de aumento do número de raízes com as crescentes concentrações do regulador vegetal.

Para a variável comprimento das três maiores raízes por estaca, houve interação significativa entre as espécies e concentrações de IBA, sendo que as duas espécies responderam diferentemente à concentração do regulador vegetal utilizada. Para $C$. tweedii não foi observado efeito significativo da aplicação de IBA sobre o comprimento das três maiores raízes. Já para $C$. brevipes, a concentração de $0 \mathrm{mg} \mathrm{L}^{-1}$ de IBA apresentou a maior média para o comprimento de raízes, não diferindo estatisticamente de $1500 \mathrm{mg} \mathrm{L}^{-1}$; entretanto, as maiores concentrações do regulador vegetal (3000 e $6000 \mathrm{mg} \mathrm{L}^{-1}$ de IBA) causaram redução no comprimento das raízes.

A redução do comprimento das raízes observado em $C$. brevipes pode indicar um efeito inibitório da auxina sobre o desenvolvimento das raízes, apesar de Hartmann et al. (2014) descreverem o IBA como não tóxico em uma ampla faixa de concentração, para a maior parte das espécies vegetais. Entretanto, além da concentração, o efeito das auxinas sintéticas depende da sensibilidade do tecido, estádio fisiológico e espécie vegetal (Grossmann 2010). Assim, em altas concentrações a auxina pode ter causado toxidez nas estacas de $C$. brevipes, resultando em menores comprimentos de raízes. Wendling e Xavier (2005) também observaram efeito inibitório do IBA na miniestaquia de Eucalyptus grandis, sendo que as maiores concentrações da auxina sintética causaram redução da sobrevivência das mudas aos 50 dias e redução de matéria seca da parte aérea em alguns clones estudados.

Assim, pode-se dizer que para C. brevipes, o regulador vegetal promoveu o desenvolvimento de maior número de raízes, porém, estas apresentaram comprimentos menores nas concentrações mais altas de IBA. Já para $C$. tweedii a aplicação de IBA acarretou em maior número de raízes por estaca, mas não teve efeito sobre o comprimento das três maiores raízes. Dessa forma, a concentração de $1500 \mathrm{mg} \mathrm{L}^{-1}$ de IBA seria a mais indicada para ambas as espécies, buscando maximizar o número e o comprimento de raízes por estaca.

Tabela 1. Resumo da ANOVA para as variáveis estacas enraizadas (\%), número de raízes por estaca $\left(\mathrm{n}^{\circ}\right)$, comprimento das três maiores raízes por estaca - CRE $(\mathrm{cm})$, retenção de folhas (\%), emissão de brotações (\%), estacas com calos, vivas e mortas (\%) para os fatores espécie e concentrações de ácido indolbutírico (IBA).

\begin{tabular}{ccccccccc}
\hline Fatores & Enraizadas & $\mathbf{N}^{\mathbf{0}}$ raízes & CRE & $\begin{array}{c}\text { Retenção } \\
\text { de folhas }\end{array}$ & Brotações & Calos & Vivas & Mortas \\
\hline Espécie & $1,9 \times 10^{-5 *}$ & $2,4 \times 10^{-6 *}$ & $2,2 \times 10^{-9 *}$ & $0,0011^{*}$ & $5,6 \times 10^{-9 *}$ & $0,0056^{*}$ & $0,0386^{*}$ & $0,0033^{*}$ \\
IBA & 0,751 & $0,0017^{*}$ & 0,0676 & 0,816 & 0,265 & 0,554 & 0,716 & 0,983 \\
Interação & 0,928 & 0,563 & $0,0069^{*}$ & 0,542 & 0,754 & 0,891 & 0,716 & 0,983 \\
\hline CV $(\%)$ & 21,75 & 31,32 & 23,10 & 23,01 & 24,08 & 98,82 & 260,61 & 175,99 \\
\hline
\end{tabular}

*Significativo ao nível de $P<0,05$. CV (\%) - Coeficiente de variação. 
Tabela 2. Porcentagem de estacas enraizadas (\%), número de raízes por estaca $\left(\mathrm{n}^{\circ}\right)$, comprimento das três maiores raízes por estaca $(\mathrm{cm})$, retenção de folhas $(\%)$, emissão de brotações $(\%)$, estacas com calos, vivas e mortas $(\%)$ de Calliandra brevipes e Calliandra tweedii em diferentes concentrações de ácido indol butírico (IBA).

\begin{tabular}{|c|c|c|c|c|c|}
\hline \multicolumn{6}{|c|}{ Estacas enraizadas (\%) } \\
\hline \multicolumn{6}{|c|}{ IBA $\left(\mathrm{mg} \mathrm{L}^{-1}\right)$} \\
\hline Espécies & 0 & 1500 & 3000 & 6000 & Média \\
\hline C. brevipes & 96,67 & 100,00 & 90,00 & 96,67 & $95,83 \mathrm{~A}$ \\
\hline C. tweedii & 65,00 & 68,33 & 60,00 & 63,33 & $64,17 \mathrm{~B}$ \\
\hline Média & $80,83 \mathrm{a}$ & 84,16 a & $75,00 \mathrm{a}$ & $80,00 \mathrm{a}$ & - \\
\hline \multicolumn{6}{|c|}{ Número de raízes por estaca $\left(\mathrm{n}^{0}\right)$} \\
\hline C. brevipes & 10,88 & 16,22 & 21,00 & 18,98 & $16,76 \mathrm{~A}$ \\
\hline C. tweedii & 5,42 & 8,57 & 8,64 & 11,40 & $8,50 \mathrm{~B}$ \\
\hline Média & $8,15 \mathrm{~b}$ & $12,39 a b$ & $14,82 \mathrm{a}$ & $15,19 \mathrm{a}$ & - \\
\hline \multicolumn{6}{|c|}{ Comprimento das três maiores raízes por estaca $(\mathrm{cm})$} \\
\hline C. brevipes & $6,70 \mathrm{Aa}$ & $5,35 \mathrm{Aab}$ & $4,64 \mathrm{Ab}$ & $4,46 \mathrm{Ab}$ & - \\
\hline C. tweedii & $2,10 \mathrm{Ba}$ & $2,82 \mathrm{Ba}$ & $2,48 \mathrm{Ba}$ & $2,72 \mathrm{Ba}$ & - \\
\hline \multicolumn{6}{|c|}{ Retenção de folhas (\%) } \\
\hline C. brevipes & 98,33 & 93,33 & 91,67 & 90,00 & $93,33 \mathrm{~A}$ \\
\hline C. tweedii & 68,33 & 68,33 & 68,33 & 71,67 & $69,17 \mathrm{~B}$ \\
\hline Média & $83,33 \mathrm{a}$ & $80,83 \mathrm{a}$ & $80,00 \mathrm{a}$ & $80,83 \mathrm{a}$ & - \\
\hline \multicolumn{6}{|c|}{ Emissão de brotações (\%) } \\
\hline C. brevipes & 98,33 & 96,67 & 95,00 & 91,67 & $95,41 \mathrm{~A}$ \\
\hline C. tweedii & 53,33 & 58,33 & 25,00 & 46,67 & $45,83 \mathrm{~B}$ \\
\hline Média & $75,83 \mathrm{a}$ & $77,50 \mathrm{a}$ & $60,00 \mathrm{a}$ & $69,16 \mathrm{a}$ & - \\
\hline \multicolumn{6}{|c|}{ Estacas com calos (\%) } \\
\hline C. brevipes & 3,33 & 0,00 & 10,00 & 3,33 & $4,16 \mathrm{~B}$ \\
\hline C. tweedii & 13,33 & 10,00 & 15,00 & 15,00 & $13,33 \mathrm{~A}$ \\
\hline Média & $8,33 \mathrm{a}$ & $5,00 \mathrm{a}$ & $12,50 \mathrm{a}$ & $9,17 \mathrm{a}$ & - \\
\hline \multicolumn{6}{|c|}{ Estacas vivas (\%) } \\
\hline C. brevipes & 0,00 & 0,00 & 0,00 & 0,00 & $0,00 \mathrm{~B}$ \\
\hline C. tweedii & 1,67 & 0,00 & 3,33 & 1,67 & $1,67 \mathrm{~A}$ \\
\hline Média & $0,83 \mathrm{a}$ & $0,00 \mathrm{a}$ & $1,67 \mathrm{a}$ & $0,83 \mathrm{a}$ & - \\
\hline \multicolumn{6}{|c|}{ Estacas mortas (\%) } \\
\hline C. brevipes & 0,00 & 0,00 & 0,00 & 0,00 & $0,00 \mathrm{~B}$ \\
\hline C. tweedii & 20,00 & 21,67 & 21,67 & 20,00 & $20,83 \mathrm{~A}$ \\
\hline Média & $10,00 \mathrm{a}$ & $10,83 \mathrm{a}$ & $10,83 \mathrm{a}$ & $10,00 \mathrm{a}$ & - \\
\hline
\end{tabular}

Médias seguidas pela mesma letra, minúscula na linha e maiúscula na coluna, não diferem entre si pelo teste de Tukey $(P<0,05)$.

\section{Efeitos das espécies}

Houve diferença significativa entre as espécies para todas as variáveis (Tabela 2). $C$. brevipes obteve a maior porcentagem de estacas enraizadas, 95,83\%, enquanto $C$. tweedii apresentou 64,17 \%. As taxas de enraizamento elevadas encontradas para $C$. brevipes corroboram com os trabalhos de Lima et al. (2006) e Mayer et al. (2008), que indicam que a espécie é de fácil enraizamento.
Já C. tweedii apresenta dificuldade de enraizamento, possivelmente devido a presença de uma camada contínua de fibras pericíclicas e ausência de armazenamento de amido (Mayer et al. 2008). No entanto, no presente estudo $C$. tweedii apresentou taxa de enraizamento de $65 \%$ no tratamento controle (0 mg L $\mathrm{m}^{-1}$ de IBA), média superior às encontradas na literatura. Lima et al. (2006) obtiveram apenas 6,7 \% de enraizamento para a espécie sem a aplicação de 
reguladores vegetais e para Mayer et al. (2008) o enraizamento foi de $23,3 \%$ no tratamento controle.

A taxa de enraizamento elevada para $C$. tweedii nesse estudo e o efeito não significativo das concentrações de IBA, evidenciam que outros fatores podem influenciar na rizogênese da espécie. Deve-se lembrar que o processo de enraizamento depende de um balanço adequado entre auxinas, giberelinas, citocininas e cofatores do enraizamento (Hartmann et al. 2014). Além disso, fatores inerentes à planta matriz, como condição nutricional, estádio fisiológico, nível endógeno de inibidores, juvenilidade, maturidade, época do ano e genótipo, podem impactar diretamente no enraizamento de propágulos (Dias et al. 2012). Assim, o enraizamento da espécie pode ter sido favorecido por outros aspectos não considerados aqui e que podem ser abordados em trabalhos futuros, como a coleta de ramos de diferentes matrizes e ao longo das épocas do ano.

C. brevipes apresentou maior média de número de raízes por estaca, quando comparada com C. tweedii. Quanto ao comprimento das três maiores raízes, $C$. brevipes também apresentou médias de comprimento de raízes estatisticamente superiores a C. tweedii em todas as concentrações de IBA. Além disso, as raízes de $C$. tweedii apresentaram aspecto de friáveis ou hiperidrícas, se mostrando muito frágeis e quebradiças, em todos os tratamentos estudados (Figura 1B, D, F, H), o que pode comprometer a qualidade do sistema radicial e posterior crescimento das mudas. A hiperidricidade, ou acúmulo anormal de água em células e tecidos vegetais, é uma desordem metabólica comum em micropropagação, sendo relacionada a vários fatores, entre eles, a espécie (Vasconcelos et al. 2012) e reguladores vegetais, como citocininas (Coste et al. 2011)

A retenção das folhas nas estacas foi influenciada pela espécie. $C$. tweedii manteve as folhas em 69,17\% das estacas enquanto $C$. brevipes manteve em 93,33\%. A importância das folhas para o processo de enraizamento já foi comprovada para outras espécies, como em estudo com estaquia de Luehea divaricata, no qual as estacas confeccionadas sem folhas apresentaram $100 \%$ de mortalidade, não ocorrendo enraizamento neste tratamento (Pacheco; Franco, 2008). Hartmann et al. (2014) afirmam que a taxa de enraizamento pode estar relacionada à retenção das folhas originais, visto que o enraizamento é favorecido pela presença de folhas, que produzem carboidratos e auxinas, e posteriormente estes são transportados do ápice para a base da estaca.

Para emissão de novas brotações, observa-se que $C$. brevipes apresentou quase que a totalidade das estacas com brotações $(95,41 \%)$, enquanto em C. tweedii apenas 45,83\% das estacas emitiram brotações. A menor porcentagem de emissão de brotações em $C$. tweedii pode ser consequência da menor taxa de enraizamento e também pela fenologia da espécie, que se apresentava com floração e frutificação no momento da coleta dos ramos. Sabe-se que estacas coletadas de plantas matrizes em sua fase reprodutiva tendem a enraizar menos devido à mobilização das reservas para os órgãos reprodutivos além de um maior acúmulo de giberelinas em detrimento a auxinas (Fachinello et al. 2005).

Ambas as espécies apresentaram estacas com calos $(13,33 \%$ em $C$. tweedii e $4,16 \%$ em $C$. brevipes) e também foi observado que a maior parte das estacas enraizadas possuía calos. Mayer et al. (2008) concluíram que a raiz tem origem direta em ambas as espécies, entretanto, o desenvolvimento de calos em $C$. tweedii parece ser essencial para a formação de raízes adventícias, mesmo que não tenham sido identificadas a formação de meristemóides nesses tecidos. Em $C$. brevipes não foram observadas estacas mortas após os 65 dias de experimento; já $C$. tweedii apresentou mortalidade de $20,8 \%$.

\section{Conclusões}

A aplicação de ácido indol butírico não influenciou na porcentagem de enraizamento, mas proporcionou maior número de raízes para ambas as espécies. No entanto, para $C$. brevipes altas concentrações de IBA causaram redução no comprimento das raízes. Assim, objetivando o melhor desenvolvimento do sistema radicial, recomenda-se a aplicação de IBA na concentração de $1500 \mathrm{mg} \mathrm{L}^{-1}$ para o enraizamento de estacas caulinares semilenhosas de $C$. brevipes e $C$. tweedii. As espécies avaliadas apresentaram resultados satisfatórios no processo de enraizamento, sendo que $C$. brevipes apresentou maior taxa de enraizamento $(95,83 \%)$ que C. tweedii $(64,17 \%)$.

\section{Agradecimentos}

Agradecemos ao Conselho Nacional de Desenvolvimento Científico e Tecnológico (CNPq) pela concessão das bolsas aos autores. 


\section{Calliandra brevipes}
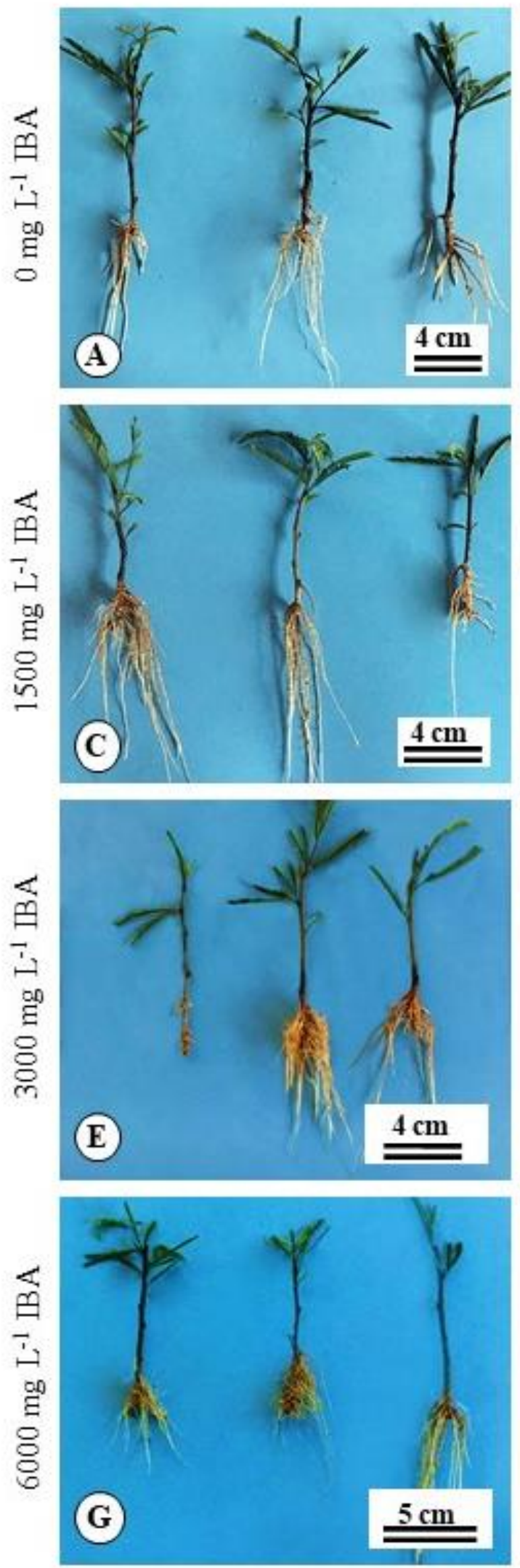

Calliandra tweediei
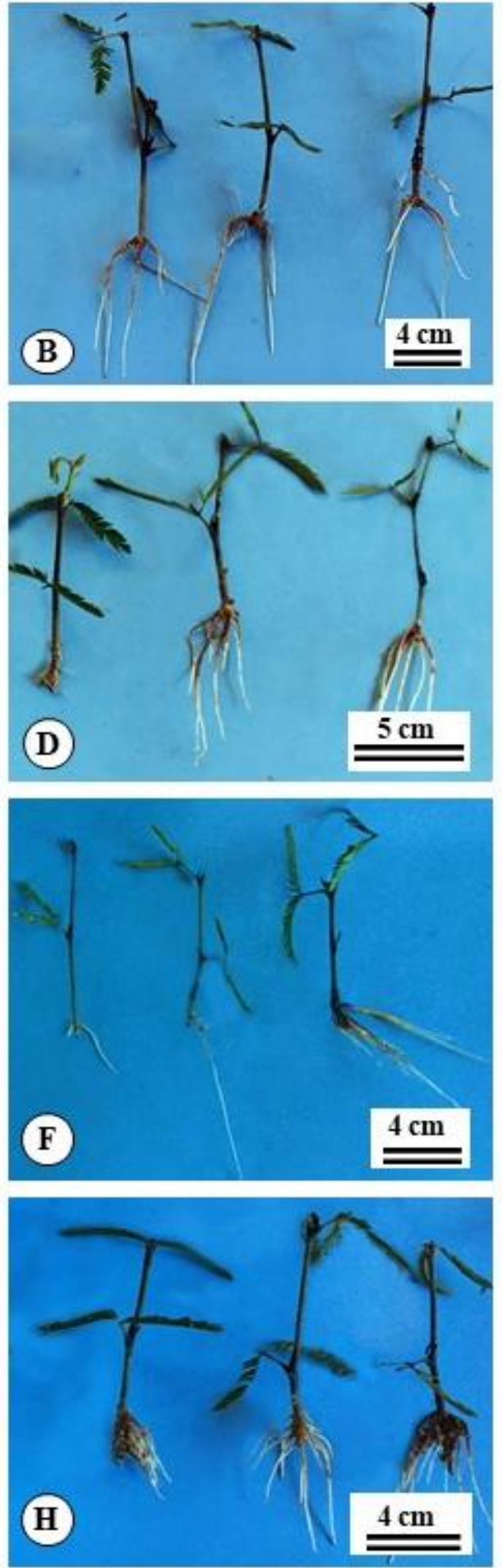

Figura 1. Estacas enraizadas de Calliandra brevipes e Calliandra tweedii submetidas a quatro concentrações de IBA. Coluna esquerda: C. brevipes; Coluna direita: $C$. tweedii. A e B: $0 \mathrm{mg} \mathrm{L}^{-1} \mathrm{IBA} ; \mathrm{C}$ e D: $1500 \mathrm{mg} \mathrm{L}^{-1} \mathrm{IBA}$; E e F: $3000 \mathrm{mg} \mathrm{L}^{-1} \mathrm{IBA}$; G e H: $6000 \mathrm{mg} \mathrm{L}{ }^{-1}$ IBA. 


\section{Referências}

Bitencourt J, Zuffellato-Ribas KC, Wendling I, Koehler HS (2009) Enraizamento de estacas de ervamate (Ilex paraguariensis A. St.-Hill.) provenientes de brotações rejuvenescidas. Revista Brasileira de Plantas Medicinais, 11(3): 277-281. doi: 10.1590/S1516-05722009000300008.

Cardoso FS, Mossanek EAO, Acra LA (2007) Biologia floral de Calliandra tweedii Benth. (Fabaceae Benth.). Estudos de Biologia, 29(68/69): 283-289. doi: 10.7213/reb.v29i68/69.22779.

Coste A, Vlase L, Halmagyi A, Deliu C, Coldea G (2011) Effects of plant growth regulators and elicitors on production of secondary metabolites in shoot cultures of Hypericum hirsutum and Hypericum maculatum. Plant Cell, Tissue and Organ Culture, 106(1): 279-288. doi: 10.1007/s11240-011-9919-5.

Dias PC, Oliveira LS, Xavier A, Wendling I (2012) Estaquia e miniestaquia de espécies florestais lenhosas do Brasil. Pesquisa Florestal Brasileira, 32(72): 453-462. doi: 10.4336/2012.pfb.32.72.453.

Erturk Y, Ercisli S, Haznedar A,Cakmakci R (2010) Effects of plant growth promoting rhizobacteria (PGPR) on rooting and root growth of kiwifruit (Actinidia deliciosa) stem cuttings. Biological Research, 43(1): 91-98.

doi: 10.4067/S0716-97602010000100011.

Fachinello JC, Hoffmann A, Nachtigal JC (2005) Propagação de plantas frutíferas. Brasília: Embrapa Informação Tecnológica. 221p.

Grossmann K (2010) Auxin herbicides: current status of mechanism and mode of action. Pest Management Science, 66(2): 113-120. doi: 10.1002/ps.1860.

Hartmann HT, Kester DE, Davies Junior, FT, Geneve RL (2014) Plant propagation: principles and practices. $9^{\text {th }}$ edition. New Jersey: Englewood Clipps. 1024 p.

Konzen ER, Bergonci T, Brondani GE (2018) Produção de mudas por propagação vegetativa. In: Araujo MM, Navroski MC, Schorn LA. Produção de sementes e mudas: um enfoque à silvicultura. Santa Maria: Editora UFSM. p. 213-236.

Lima DM, Alcantara GB, Bortolini MF, Fanti FP, Biasi LA, Quoirin M, Koehler HS, Zuffellato-Ribas KC (2006) Substratos e concentrações de ácido naftaleno acético no enraizamento de estacas semilenhosas de Calliandra selloi e Calliandra tweedii. Scientia Agraria, 7(1-2): 105-111. doi: 10.5380/rsa.v7i1.7280.
Mayer JLS, Cardoso NA, Cuquel F, Bona C (2008) Formação de raízes em estacas de duas espécies de Calliandra (Leguminosae - Mimosoideae). Rodriguésia, 59(3): 487-495. Disponível em: https://www.jstor.org/stable/23499874?seq=1\#meta data_info_tab_contents. Acesso em: 20 mar. 2020.

Miotto STS, Lüdtke R, Oliveira MLAA (2008) A família Leguminosae no Parque Estadual de Itapuã, Viamão, Rio Grande do Sul, Brasil. Revista Brasileira de Biociências, 6(3): 269-290. Disponível em:http://www.ufrgs.br/seerbio/ojs/index.php/rbb/a rticle/view/1029. Acesso em: 20 mar. 2020.

Mondin CA, Eggers L, Ferreira PMA (2010) Catálogo ilustrado de plantas ornamentais da PUCRS. Porto Alegre: EdiPUCRS.

Pacheco JP, Franco ETH (2008) Substratos e estacas com e sem folhas no enraizamento de Luehea divaricata Mart. Ciência Rural, 38(7): 1900-1906.

Pacurar DI, Perrone I, Bellini C (2014) Auxin is a central player in the hormone cross-talks that control adventitious rooting. Physiologia Plantarum, 151(1): 83-96. doi: 10.1111/ppl.12171.

Vasconcelos AGV, Tomas LF, Camara TR, Willadino L (2012) Hiperidricidade: uma desordem metabólica. Ciência Rural, 42(5): 837-844. doi: 10.1590/S0103-84782012000500013.

Wendling I, Xavier A (2005) Influência do ácido indolbutírico e da miniestaquia seriada no enraizamento e vigor de miniestacas de clones de Eucalyptus grandis. Revista Árvore, 29(6): 921-930. doi: 10.1590/S0100-67622005000600011.

Xavier A, Wendling I, Silva RL (2009) Silvicultura clonal: princípios e técnicas. Viçosa: Universidade Federal de Viçosa. 272p. 